\title{
Correction to: Integration of geographic and hierarchical routing protocols for energy saving in wireless sensor networks with mobile sink
}

\author{
Shahrokh Vahabi ${ }^{1}$ (D) Mohammadreza Eslaminejad $^{1} \cdot$ Seyed Ebrahim Dashti $^{2}$
}

Published online: 28 June 2019

(C) Springer Science+Business Media, LLC, part of Springer Nature 2019

\section{Correction to: Wireless Networks (2019) 25:2953-2961} https://doi.org/10.1007/s11276-019-02015-5

The original version of this article unfortunately contained an error in the author's affiliation. The third author, Dr. Seyed Ebrahim Dashti, is currently affiliated in the Department of Computer Engineering, Jahrom Branch, Islamic Azad University, Jahrom, Iran.
Publisher's Note Springer Nature remains neutral with regard to jurisdictional claims in published maps and institutional affiliations.

The original article can be found online at https:// doi.org/10.1007/s11276-019-02015-5.

Shahrokh Vahabi

shahrokhvahabi@gmail.com

1 Information Technology Department, Zand Institute of Higher Education, Namazi St, Sattarkhan St, Shiraz, Fars Province, Iran

2 Department of Computer Engineering, Jahrom Branch, Islamic Azad University, Jahrom, Iran 